\title{
Identification of Resistant Sources in Field Evaluation of Soybean (Glycine max (L.) Merr.) Genotypes against Pod Blight and Rhizoctonia Aerial Blight
}

\author{
K.P. Singh*, T. Aravind, Pooja Bhatt and Kumari Surbhi
}

Department of Plant Pathology, College of Agriculture, G. B. Pant University of Agriculture and Technology, Pantnagar, Udham Singh Nagar, Uttarakhand-263145, India

*Corresponding author

K e y w o r d s
PB, RAB,
Resistance sources,
Soybean
Article Info
Accepted:
$\begin{aligned} & 15 \text { February } 2019 \\ & \text { Available Online: } \\ & \text { 10 March } 2019\end{aligned}$

An investigation was carried out at experimental block for soybean crops, Norman E Borlaug Crop Research Centre, Pantnagar with sixteen promising genotype of soybean to assess resistance to pod blight (PB, Colletotrichum truncatum) and Rhizoctonia aerial blight (RAB, Rhizoctonia solani). The experiment was conducted consecutively for natural infection for thirteen years during Kharif season of 2005 - 2017 following randomized block design with three replication. Results revealed that none of the genotypes showed absolute resistant or resistant reaction to either PB or RAB. Among the sixteen genotypes, only two genotypes viz., PK 262 and PK 472, were moderately resistant to both the diseases. The four genotypes viz., JS-7244, JS- 7105, Bragg and VLS- 58 showed moderately resistant reaction to PB alone. Genotype JS-93-05 was susceptible to both $\mathrm{RAB}$ and $\mathrm{PB}$. Remaining genotypes were either susceptible or moderately susceptible to both the diseases. The genotypes with moderately resistance reaction could be considered as a promising breeding material for development of high yielding blight resistant soybean variety.

\section{Introduction}

Soybean (Glycine max L. Merrill) is one of the important legume crop grown globally. It contains 40 per cent protein and 20 per cent edible oil and is aptly called the "Golden Bean or Miracle Crop". It is believed to have originated in north eastern China and later on spread to different parts of the globe. It is now a major source of protein and contributes more than 25 per cent of the total edible oil production globally (Mathpal, 2016). It is rich in unsaturated fatty acids and contains high amount of essential fatty acids like linolenic, linoleic and oleic acid (Fehr et al., 1992). India ranks fourth in area and fifth in terms of production. In India, Madhya Pradesh and Maharashtra accounts for over 89 per cent of the annual production [Anonymous 2017a]. In Uttarakhand, soybean was cultivated over an area of 11585 hectares with an overall production of 13355 metric tons during 201617. Of the 13 districts, foot hills (Tarai) account for approximately 5 per cent of total area and production of the state [Anonymous $2017 b]$. Though there is scope for enhancing 
the production of soybean in the state, biotic factors like diseases hamper their successful cultivation. The major diseases affecting the crop include Rhizoctonia aerial blight, pod blight, bacterial blight, soybean mosaic virus (SMV) and the soybean yellow mosaic virus (SYMV). Among the foliar diseases, aerial blight caused by Rhizoctonia solani Kuhn and anthracnose and pod blight caused by Colletotrichum truncatum (Schw.) Andrus \& Moore attacks the crop at all growth stages and causes heavy yield losses. The disease intensity in Uttarakhand has been found to be increasing due to changing environmental conditions and has become a concern for the farmers. Since the use of resistant varieties is the most efficient and economical way to manage plant diseases, the present study was undertaken to evaluate the germplasm against $\mathrm{PB}$ and $\mathrm{RAB}$ under natural epiphytotic conditions for 13 years to identify resistant donors which can be the potential sources for resistance breeding programmes.

\section{Materials and Methods}

Sixteen promising soybean genotypes were screened for their resistance against pod blight and Rhizoctonia aerial blight at Norman Borlaug Crop Research Center, G. B. Pant University of Agriculture and Technology, Pantnagar, Uttarakhand for 13 years from Kharif 2005 to 2017. The experiment was laid out in Randomized Block Design with three replications each. The genotypes were sown in three rows of five meter length (200 seeds per row) at $60 \mathrm{~cm}$ apart in last week of June using recommended package of practices. Starting from seedling emergence, the observations were recorded at biweekly intervals. The severity of the diseases was recorded on randomly selected 10 plants from each line. Further, based on the number of infected plants and total number of plants in each plot, per cent PB and RAB affected plants were calculated. The scoring of the test material was done when 100 per cent plants of spreader row showed disease symptoms. Phenotypic categories of resistance or susceptibility were assigned based on the visible expression of disease development. Individual selected plants were graded as per the rating scale of 0 to 9 (AICRP on Soybean). Infection types were characterized as $0=$ no visible symptoms (Absolutely Resistant); 1 (Highly Resistant $)=$ 1\%, 3 (Moderately Resistant) $=1.1-10 \%, 5$ (Moderately Susceptible) $=10.1-25 \%, 7$ (Susceptible) $=25.1-50 \%, 9$ (Highly Susceptible $)=>50$ per cent plants infected. Percentage disease index were recorded three weeks before harvest by using the formula given by Wheeler (1969). The average data of thirteen years i.e. 2005-2017 were pooled.

Percentage disease incidence $=$

(Total number of infected plants $\mathrm{x}$ 100) / (Total number of plants observed)

Percentage disease index =

(Sum of individual rating x 100) / (Total number of leaves observed $\times$ Maximum disease grade)

\section{Results and Discussion}

The experimental results revealed that the genotypes exhibit differential reaction to the two diseases (Table 1). Compared to PB, the disease pressure of $\mathrm{RAB}$ was high in most years and Pantnagar is considered as hot spot for the disease. Out of 16 genotypes screened for resistance, none of the genotypes were resistant to either of the diseases. Only two genotypes viz., PK-262 and PK-272 were moderately resistant were as three genotypes JS -72-280, NRC-7 and JS 335 were moderately susceptible to both the diseases. Genotypes JS-7244, JS-7105, Bragg and VLS-58 were moderately resistant to PB 
alone. Six genotypes viz., JS-7546, MACS58, Monetta, KHSb-2, Pb-1 and Shivalik exhibited moderately susceptible and susceptible reaction to $\mathrm{PB}$ and $\mathrm{RAB}$, respectively. Genotype JS-93-05 was susceptible to both $\mathrm{RAB}$ and $\mathrm{PB}$. In totality, susceptibility of the genotypes was higher for $\mathrm{RAB}$ with 14 genotypes showing moderately susceptible or susceptible reaction compared to eight genotypes for PB. None of the genotypes were highly susceptible to either of the disease.

The genotypes exhibited more or less similar disease reaction during different years under study with varying environmental conditions (Table 2). The severity of the diseases, RAB in particular, has increased tremendously after 2013. Except for a few years, the severity pattern was similar for both the diseases which indicate similar environmental conditions favoring the diseases. This leads to higher yield loss which makes the adoption of integrated strategies absolutely essential. But the differences in the mode of survival and spread pose a major challenge for developing an integrated strategy. Rhizoctonia solani survives as sclerotia in soil and crop debris and attacks the young leaves with vegetative stage being the most susceptible stage. It is characterized by water soaked small lesions on leaf lamina which subsequently spread in a fan shaped manner to the rest of the blade. Finally, the affected leaves gets curled and dried out (Mathpal and Singh, 2017). In contrast, Colletotrichum truncatum is seed and soil borne and attacks both the leaves (anthracnose) and pods (pod blight) with the pod blight stage being the more damaging one.

Utilization of resistant cultivars is the most effective and economical means of plant disease management. The resistant cultivars reduce cost, time and energy when compared to other methods of disease management. In the pooled data, the genotypes PK-472 and PK 262 have shown some degree of resistance to both PB and RAB and hence can be used as resistance donors in breeding programs for developing resistant commercial cultivars in soybean.

Table.1 Performance of soybean genotypes against PB and RAB

\begin{tabular}{|c|c|c|c|}
\hline \multirow{2}{*}{$\begin{array}{l}\text { Infection } \\
\text { Category }\end{array}$} & \multirow{2}{*}{$\begin{array}{l}\text { Reaction } \\
\text { Type }\end{array}$} & \multicolumn{2}{|c|}{ Genotypes } \\
\hline & & PB & $\mathrm{RAB}$ \\
\hline $\mathbf{A R}$ & 0 & - & - \\
\hline $\mathbf{R}$ & 1 & - & - \\
\hline MR & 3 & $\begin{array}{l}\text { JS-7244, JS-7105, PK-262, PK } \\
472 \text {, Bragg and VLS-58 }\end{array}$ & PK-262, PK-272 \\
\hline MS & 5 & $\begin{array}{l}\text { JS-7546, JS-72-280, MACS-58, } \\
\text { Monetta, KHSb-2, JS-335, Pb-1, } \\
\text { NRC-7 and Shivalik* }\end{array}$ & $\begin{array}{l}\text { JS-7244, JS-72-280, Bragg, NRC- } \\
\text { 7, VLS-58 and JS } 335\end{array}$ \\
\hline $\mathbf{S}$ & 7 & JS-93-05 & $\begin{array}{l}\text { JS-7546, JS-7105, JS-93-05, PB-1, } \\
\text { Monetta, KHSb-2, MACS-58 and } \\
\text { Shivalik, }\end{array}$ \\
\hline HS & 9 & - & - \\
\hline
\end{tabular}


Table.2 Year wise distribution of soybean genotypes in various infection categories

\begin{tabular}{|c|c|c|c|c|c|c|c|c|c|c|c|c|}
\hline \multirow{2}{*}{ Year } & \multicolumn{2}{|c|}{ AR } & \multicolumn{2}{c}{$\mathbf{R}$} & \multicolumn{2}{c|}{ MR } & \multicolumn{2}{c|}{ MS } & \multicolumn{3}{c|}{ S } & \multicolumn{2}{c|}{ HS } \\
\cline { 2 - 18 } & PB & RAB & PB & RAB & PB & RAB & PB & RAB & PB & RAB & PB & RAB \\
\hline $\mathbf{2 0 0 5}$ & 0 & 0 & 3 & 2 & 7 & 1 & 3 & 5 & 1 & 1 & 0 & 5 \\
\hline $\mathbf{2 0 0 6}$ & 0 & 0 & 2 & 1 & 13 & 11 & 0 & 2 & 0 & 1 & 0 & 0 \\
\hline $\mathbf{2 0 0 7}$ & 0 & 0 & 4 & 3 & 4 & 3 & 5 & 7 & 3 & 3 & 0 & 0 \\
\hline $\mathbf{2 0 0 8}$ & 1 & 0 & 5 & 2 & 8 & 7 & 1 & 5 & 0 & 0 & 0 & 0 \\
\hline $\mathbf{2 0 0 9}$ & 0 & 0 & 6 & 4 & 8 & 5 & 2 & 5 & 0 & 2 & 0 & 0 \\
\hline $\mathbf{2 0 1 0}$ & 0 & 0 & 6 & 0 & 9 & 3 & 1 & 8 & 0 & 5 & 0 & 0 \\
\hline $\mathbf{2 0 1 1}$ & 0 & 0 & 1 & 1 & 13 & 2 & 2 & 11 & 0 & 2 & 0 & 0 \\
\hline $\mathbf{2 0 1 2}$ & 0 & 0 & 2 & 2 & 13 & 2 & 0 & 12 & 1 & 0 & 0 & 0 \\
\hline $\mathbf{2 0 1 3}$ & 0 & 0 & 0 & 0 & 2 & 0 & 5 & 2 & 9 & 10 & 0 & 4 \\
\hline $\mathbf{2 0 1 4}$ & 0 & 0 & 0 & 0 & 0 & 0 & 5 & 0 & 11 & 10 & 0 & 6 \\
\hline $\mathbf{2 0 1 5}$ & 0 & 0 & 0 & 0 & 1 & 0 & 11 & 0 & 4 & 11 & 0 & 5 \\
\hline $\mathbf{2 0 1 6}$ & 0 & 0 & 0 & 0 & 0 & 0 & 4 & 1 & 11 & 5 & 1 & 10 \\
\hline $\mathbf{2 0 1 7}$ & 0 & 0 & 0 & 0 & 1 & 0 & 3 & 1 & 7 & 4 & 5 & 11 \\
\hline
\end{tabular}

Similar investigations have been carried out by other researchers as well. Chavan et al., (2018) has reported that out of 40 soybean genotypes screened for their resistance against pod blight none of the genotypes were resistant to the disease. Sixteen genotypes were moderately resistant with percent disease intensity ranging from $12.20-23.10$ were as four genotypes were moderately susceptible. Sajeesh et al., (2014) has reported that out of 11 soybean entries screened against anthracnose/ pod blight, 64 per cent genotypes showed moderately resistant reaction. Only 1 genotype viz., DSb 12 was resistant.

Similarly, Joshi et al., (2018) has screened 125 soybean entries for their resistance to major foliar diseases in North India and reported only 1 genotype (AMS 115) was resistant were as 113 entries were moderately resistant. Shrirao et al., (2009) observed that out of 16 Soybean genotypes screened against $\mathrm{RAB}$, four entries showed highly resistant reaction were as three entries were moderately resistant.
Thus, it can be concluded that there are sources of resistance to $\mathrm{PB}$ and $\mathrm{RAB}$ available in the germplasm accessions which needs to be identified. This depicts the need to screen the genotypes in hotspots for extended period of time to avoid disease escapes and to obtain true disease resistant genotypes to develop disease resistant varieties for successful cultivation of soybean especially in the endemic areas for these diseases.

\section{References}

Anonymous (2017a). SOPA's estimate of soybean crop. The Soybean Processors Association of India. http://www.sopa.org.in

Anonymous (2017b). Directorate of agriculture, Uttarakhand. http://agriculture.uk.gov.in

Chavan, S. S., Shinde, D. A. and Kadam, A. M. 2018. Screening of soybean genotypes against Colletotrichum truncatum. J. Pharmacogn. Phytochem. SP1: 2972-2974.

Fehr, W. R., Welke, E. G., Hammond, D. N., 
Duvick, D. N. and Cianzio, S. R. 1992. Inheritance of reduce linolenic acid content in soybean genotypes A16 and A17. Crop Sci. 32: 903-906.

Joshi, D., Singh, P., Singh, K., Adhikari, S. and Rani, S. 2018. Screening of soybean germplasm for important diseases prevalent in North India. Int. J. Chem. Stud. 6(2): 2731-2733.

Mathpal, M. 2016. Epidemiology and management of Rhizoctonia aerial blight of soybean (Glycine max (L.) Merrill). PhD Thesis, G. B. Pant University of Agriculture and Technology, Pantnagar, Uttarakhand. $14 \mathrm{pp}$.

Mathpal, M. and Singh, K. P. 2017.
Prevalence and severity of Rhizoctonia aerial blight of soybean in Uttarakhand. Indian J. Ecology, 44:417-419

Sajeesh, P. K., Rao, M. S. L. and Shamarao, J. 2014. Screening of soybean (Glycine $\max$ (L.) Merill) genotypes against purple seed stain and anthracnose disease. Environ. Ecol. 32(3A): 10921095.

Shrirao, A. V., Gawade, R. A., Khote, A. C. 2009. Evaluation of soybean genotype against the major soybean disease. $J$. Pl. Dis. Sci. 4(1): 92 -94.

Wheeler, B. E. J .1969. An introduction to plant diseases. John Wiley and Sons Ltd., London.

\section{How to cite this article:}

Singh, K.P., T. Aravind, Pooja Bhatt and Kumari Surbhi. 2019. Identification of Resistant Sources in Field Evaluation of Soybean (Glycine $\max$ (L.) Merr.) Genotypes against Pod Blight and Rhizoctonia Aerial Blight. Int.J.Curr.Microbiol.App.Sci. 8(03): 1823-1827. doi: https://doi.org/10.20546/ijcmas.2019.803.215 